\title{
Dilution Effect on the Extinction of Impinging Diffusion Flame with a Lateral Wall
}

\author{
Nadjib Ghiti*, Abed Alhalim Bentebbiche, Ramzi Boulkroune \\ Institute of Mechanical Engineering, USTHB University of Science and Technology, Algiers, Algeria \\ *Corresponding author: ghitinadjib@yahoo.fr
}

Received December 24, 2012; Revised February 26, 2013; Accepted April 09, 2013

\begin{abstract}
The dynamic process of the interaction between a turbulent jet methane diffusion flame and a lateral wall was experimentally studied. The evolution of the flame temperature field with the Nitrogen dilution of the methane jet flame was studied for $0.2 \mathrm{~N}_{2}, 0.4 \mathrm{~N}_{2}, 0.6 \mathrm{~N}_{2}, 0.8 \mathrm{~N}_{2}$, the interaction between the diffusion flame and the lateral wall is characterized for different distance between the wall and the central axis of the jet flame, the dilution is found to play the central role in the flame extinction process. The flame response as the lateral wall approaches from infinity and the increasing of the dilution rate make the flame extinction more rapidly than the flame without dilution, when the nitrogen dilution rate increase the flame temperature decrease.
\end{abstract}

Keywords: flame, dilution, impinging, infrared thermography, methane

\section{Introduction}

Flame extinction is important for both turbulent combustion [1] and fire safety [2]. Based on the mechanism, extinction of non-premixed flame can be roughly categorized into four different types [1]. Due to increase of the velocity gradient at the vicinity of the flame surface, the residence time of the reactants is decreased and extinction in this manner can be called extinction by strain. In non-premixed combustion, excessive dilution of one of the reactants can increase the chemical reaction time and ultimately lead to extinction, which can be called extinction by dilution. In some cases, where the flame surface is pushed very close to a nonadiabatic wall, heat loss starts to prevail and flame temperature decreases. As a consequence, the chemical reaction time decreases and eventually leads to extinction, which can be called extinction by convective heat transfer. Under certain conditions, e.g. opposed-jet flame at low strain rate and with the absence of buoyancy, the flame thickness becomes large, and radiative heat loss from the large high temperature zone starts to dominate. Similar to that of the convective heat losses, the decrease in flame temperature reduces the chemical reaction time and produces extinction by radiation. The review here is focused on the second and the third combined effect of extinction.

An experimental and computational investigation [3] aimed at understanding and quantifying the source of uncertainties associated with such characterization of extinction limits of fuel-air mixtures, ranging from low extinction strain rate methane-air flames to highextinction strain rate ethylene-air flames. Experiments were conducted at various nozzle separation distances to investigate potential differences in axial velocity profiles along the axial and radial directions and the corresponding local extinction strain rates. The slope of axial velocity in the axial and radial directions at the air outlet boundary was found to increase with decreasing nozzle separation distance. The variation of local extinction strain rate with changes in separation distance was within the uncertainty of experimental data.

An experimental study was conducted by [4] to investigate a laminar flame speeds and extinction strain rates of benzene, $\mathrm{n}$-propylbenzene, toluene, $\mathrm{o-}, \mathrm{m}-$, and $\mathrm{p}$ xylene, and 1,2,4- and 1,3,5-trimethylbenzene flames in the counter flow configuration under atmospheric pressure. The experimental data revealed that the aromatic fuel structure plays a critical role on flame propagation, with the laminar flame speed decreasing with an increase in methylation of benzene but the extinction data revealed a more discriminative effect arising from fuel structure differences.

The kinetic effects of low temperature non-equilibrium plasma assisted $\mathrm{CH}_{4}$ oxidation on the extinction of partially premixed methane flames was studied by [5] The experiments showed that non-equilibrium plasma can dramatically accelerate the $\mathrm{CH}_{4}$ oxidation at low temperature. The rapid $\mathrm{CH}_{4}$ oxidation via plasma assisted combustion resulted in fast chemical heat release and extended the extinction limits significantly.

An experimental study based on high-speed (HS) images of OH-PLIF of a turbulent diffusion flame of a compressed natural gas CNG conducted by [6] they are found Three types of structures, common to all the flames studied in this experiment, are identified: 'breaks', 'closures' and 'growing kernels'. Events of 'breaks' are counterbalanced by the occurrence of 'closures' which reconnect the flame sheet and maintain stable combustion particularly in the upstream regions of flames.

The study [7] of the extinction limits and emission formations of dry syngas $\left(50 \% \mathrm{H}_{2}-50 \% \mathrm{CO}\right)$, moist syngas 
(40\% $\mathrm{H}_{2}-40 \% \quad \mathrm{CO}-20 \% \quad \mathrm{H}_{2} \mathrm{O}$ ), and impure syngas containing $5 \% \mathrm{CH}_{4}$. A counter flow flame configuration was numerically investigated to understand extinction and emission characteristics at the lean-premixed combustion condition by varying dilution levels $\left(\mathrm{N}_{2}, \mathrm{CO}_{2}\right.$ and $\left.\mathrm{H}_{2} \mathrm{O}\right)$ at different pressures and syngas compositions. $\mathrm{CO}_{2}$ diluted flame has the same extinction limit in moist syngas as in dry syngas but a higher extinction temperature; $\mathrm{H}_{2} \mathrm{O}$ presence in the fuel mixture decreases the extinction limit of $\mathrm{N}_{2}$ diluted flame but still increases the flame extinction temperature; impure syngas with $\mathrm{CH}_{4}$ extends the flame extinction limit but has no effect on flame temperature in $\mathrm{CO}_{2}$ diluted flame; for diluted moist syngas, extinction limit is increased at higher pressure with the larger extinction temperature; for different compositions of syngas, higher $\mathrm{CO}$ concentration leads to higher NO emission. A numerical investigation by [8] was developed to study the interaction between the diffusion flame and a lateral wall and they found that the flame structure is more influenced by the wall.

The aims of this work are to study the effect of the addition of the inert gas to the methane jet flame on the extinction behavior.

\section{Temperature Measurement}

In flames, the temperature profile provides very useful information because the flame structure, consisting of species concentrations, density, pressure, and velocity, is associated with temperature. Especially in this study, measuring flame temperature accurately was one of the key issues to estimate the temperature fluctuation and RMS root mean square to evaluate the flame extinction based on the RMS calculation. There are several techniques available for temperature measurement: infrared thermography, sonic thermometry, and Laser scattering thermometry. Our experiment is based on the infrared thermography technique now is the most widely used method because of its accuracy and safety.

\section{Experimental Apparatus and Data Reduction}

The equipment for our experiments consists of an infrared thermal imaging system, an impinging jet system, a and an impinging plate of $10 \mathrm{~mm}$ in thickness, and a system to measure flow rate and pressure for both of methane and nitrogen gas. A schematic diagram appears in Figure 1 the infrared thermal imaging system (FLIR systems_ ThermaCAMA40M camera and ThermaCAM Research software) has a range of temperature measurement from $300 \mathrm{C}^{\circ}$ to $2000 \mathrm{C}^{\circ}$ with $\pm 2 \%$ accuracy. The IR camera utilizes a $320 \cdot 240$ pixels uncooled focal plane array detector operated over the wavelength range from $7.5 \mu \mathrm{m}$ to $13 \mu \mathrm{m}$. The field of view is $24^{\circ} * 18^{\circ}$, the instantaneous field of view is $1.3 \mathrm{mrad}$, and the thermal sensitivity is $0.1 \mathrm{C}^{\circ}$ at $30 \mathrm{C}^{\circ}$. Images is transferred to a computer in almost real time and stored therein for further analysis.

\section{Results and Discusion}

\subsection{Temperature Impinging Flame Field}

The length of the impinging flame decreases as the $\mathrm{N}_{2} / \mathrm{CH}_{4}$ mixture ratio is increased. The blue area occupies nearly the entire impinging flame for a mixture ratio of 1 . This shows that the nitrogen gas molecules dilute the local methane fuel concentration, which produces better combustion.

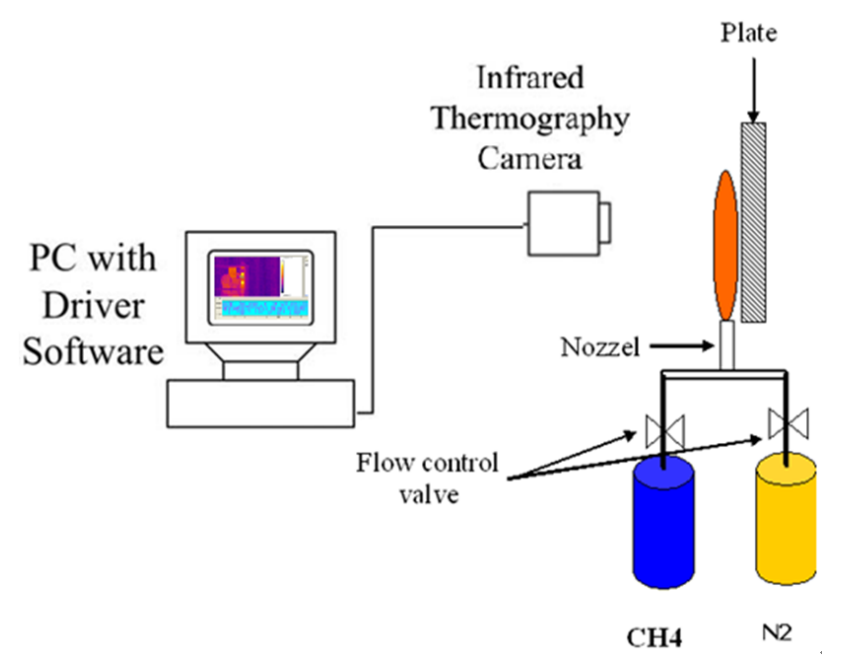

Figure 1. The schematic diagram of the experimental apparatus

When the methane flame mixes with nitrogen gas. These flow fields are similar to the cold flow of jet impinging flow [9]. It is evident that the flame stretch might be destroyed by the inert gas, nitrogen. The nitrogen molecules mix with the methane flame and break down the stretch mechanism. In the diffusion flame, a weaker stretch boundary may enhance the mixing rate between the fuel and oxidizer. The fluctuation phenomenon can, therefore, be improved Figure 2.

Unlike the free jet, the wall jet is constantly generating vortices due to the presence of a solid boundary.

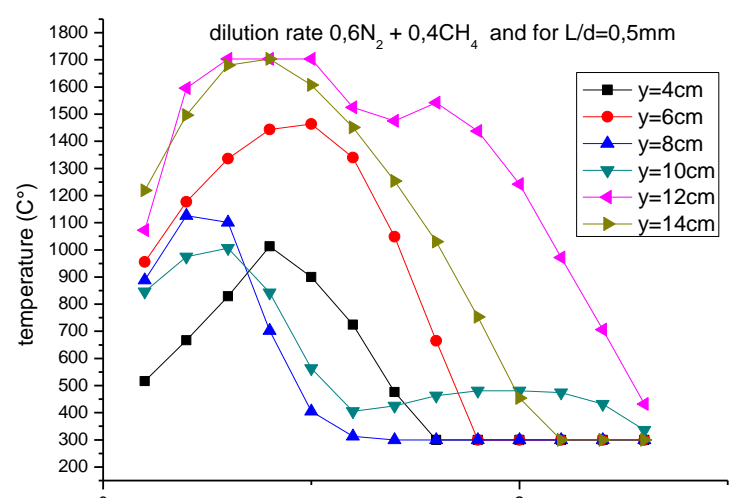

Figure 2. Methane diluted flame for $0.6 \mathrm{~N}_{2} / 0.4 \mathrm{CH}_{4}$

Figure 3 illustrates the temperature distribution along the centerline of the impinging flame mixed with different inert gas ratios.

Figure 3 illustrates the maximum temperature location for every case in the cross section. The location of the flame sheet is also shown. The results show that the pure methane impinging flame exhibits a symmetrical conical shape. The flame configuration becomes asymmetrical as the proportion of non-reactive gas in the fuel is increased. 
The stretch force of the flame also becomes weaker when mixed with nitrogen gas.

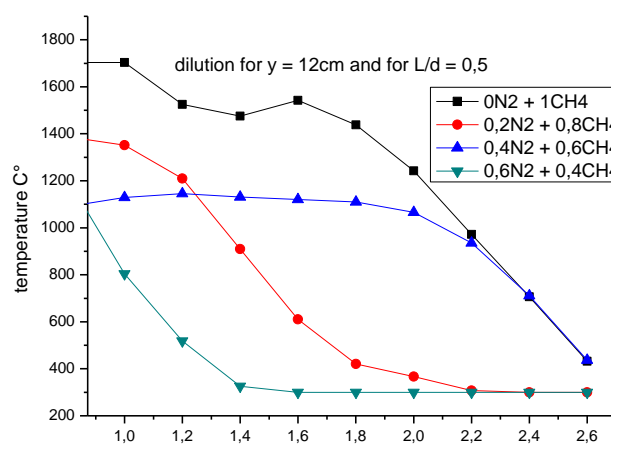

Figure 3. Methane non premixed flame for different nitrogen dilution rate

\subsection{Extinction by Dilution and Impinging Effects}

The effects of equivalence ratio, bulk velocity and nozzle to plate separation were examined with reference to the nitrogen/methane dilution effects $0.2 / 0.8 ; 0.4 / 0.6$; $0.6 / 0.4 ; 0.8 / 0.2 ; 0 / 1$, for the same methane jet diameter $10 \mathrm{~mm}$, smaller bulk velocities or larger nozzle separations flame to the wall, which eventually extinguished with leaner mixtures between air and methane caused by dilution effect and higher velocities or smaller separations.

Nozzle separations of $\mathrm{L} / \mathrm{d}=1$ or greater had nearuniform profiles of temperature because at this distance the wall has no influence on the flame structure, while smaller values like $\mathrm{L} / \mathrm{d}=0.5$ lead to an increase from the axis to a peak at the edge of the impingement region. The amplitude of the peak frequency increased as the separation was reduced. Thus, the flames quenched from large to small radius at the smaller separations. Complete extinction occurred when the mixture between nitrogen and methane is greater than $0.4 \%$. The dilution rates at the impingement plane were at least $40 \%$ greater with combustion than with isothermal flow and caused incomplete combustion and extinction, lower temperatures caused by high dilution rates and smaller distance between the flame and the impinging plate Figure 5.

When the amplitude of the temperature fluctuations was further increased by oscillations, the flame detached more rapidly and the flame extinction rate decreased. A reduction in the frequency of oscillations had the same effect and extinction times were greatly reduced by modest increases in bulk velocity or a reduction in nozzle separation distance.

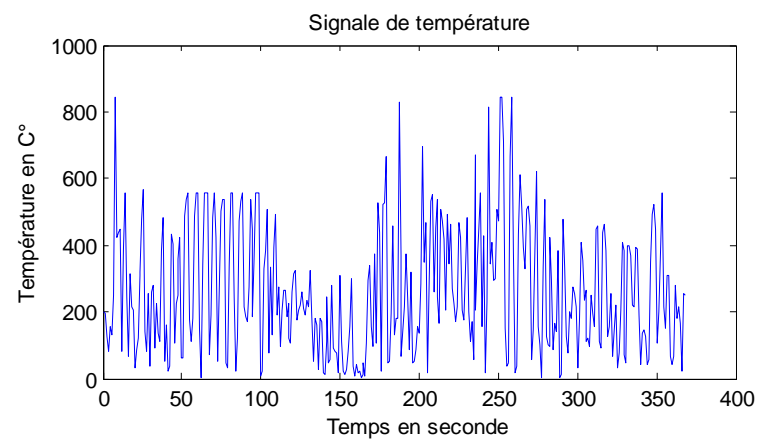

Figure 4. Temperature signal for $0 \mathrm{~N}_{2}+1 \mathrm{CH}_{4}$
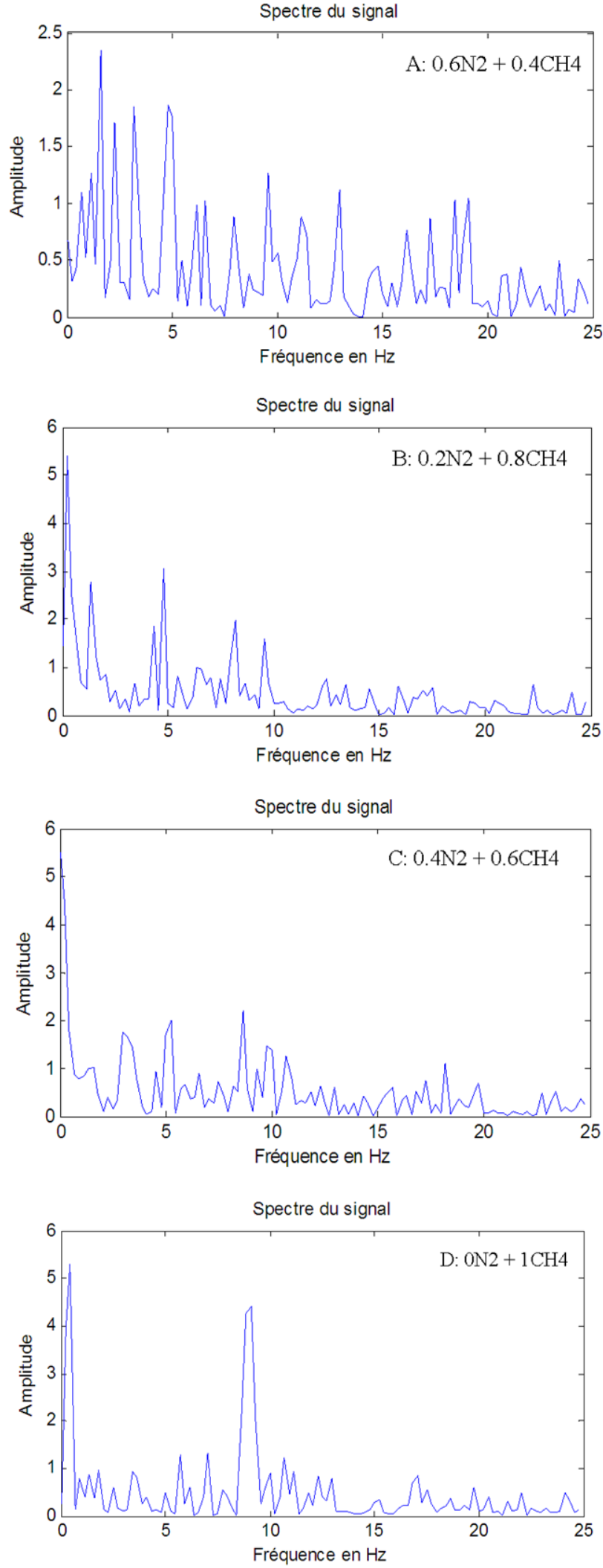

Figure 5. Spectral of temperature fluctuation at the same point for different nitrogen dilution rate for $\mathrm{L} / \mathrm{d}=0.5$ (A, B, C, D)

The Figure 6 showed the influence of the reacting flow flame structure by the dilution effect and the wall impinging the RMS of the flame was varied with the distance from the wall when the measure point is far from the wall the RMS has the great values and when the point is more near the impinging wall the RMS value decrease because just behind the wall more friction produced and the vortex is dissipated. 


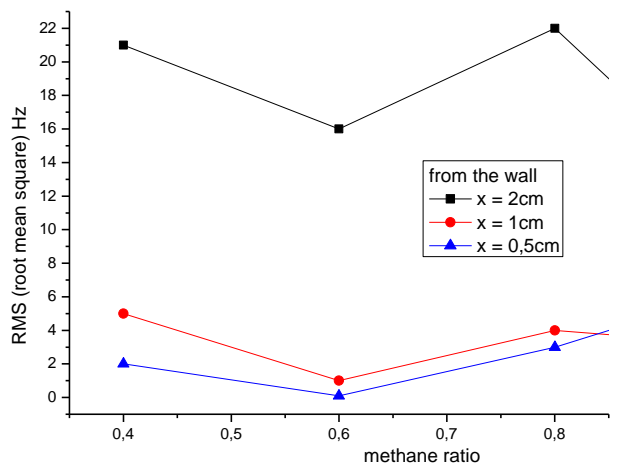

Figure 6. Root mean square RMS value for combined effect of nitrogen dilution rate and the impinging wall

The width of the different impinging gases flame is increased due to the momentum of the nitrogen gas. When the nitrogen fraction rates increase the detached flame length increase is $1 \mathrm{~cm}$ for $0.2 \mathrm{~N}_{2}$ and $4 \mathrm{~cm}$ for $0.6 \mathrm{~N}_{2}$.

\section{Conclusion}

An experimental investigation using an infrared thermography technique on improving the diffusion rate by introducing inert gas into an impinging flame was executed. The conical shape of the diffusion jet flame was destroyed and the stretch effect was weakened as the methane fuel mixed with the nitrogen gas. The flame structure was that of a plane flame. It is interesting to note that the non-reactive gas, nitrogen gas, spread the flame to a shape similar to that of the cold flow condition. The results show that the inert gas increased the diffusion rate in the reaction process. The flame became bluer and shorter. The fluctuation rate at the tip of the conical flame was also reduced. The blue flame is more stable than the pure diffusion flame. The results suggest that the inert gas does not interact with the reaction flow but does impact the diffusion rate.

It is also interesting to note that the temperature of the impinging flame becomes similar to that of the pure methane flame as the nitrogen gas mixture ratio is increased. The RMS temperature is more influenced with nitrogen addition more dilution we will obtain the flame extinction.

\section{Acknowledgment}

The Authors wish to thank for the fully financial support from the Research center for welding and metallurgical. URASM-CSC - Annaba- ALGERIA

\section{References}

[1] F. A. Williams, "Progress in Knowledge of Flamelet Structure and Extinction", Progress in Energy and Combustion Science 26, 2000 pp. 657-682.

[2] Williams, F. A. "A Review of Flame Extinction", Fire Safety Journal 3,1981, pp. 163-175.

[3] B.G. Sarnacki, G. Esposito, R.H. Krauss, H.K. Chelliah "Extinction limits and associated uncertainties of nonpremixed counter flow flames of methane, ethylene, propylene and n-butane in air", Combust.Flame, 159(3), 1026-1043, 2012.

[4] Chunsheng Ji, Enoch Dames, Hai Wang, Fokion N. Egolfopoulos "Propagation and extinction of benzene and alkylated benzene flames", Combust. Flame, 159(3), 1070-1081, 2012.

[5] Wenting Sun, Mruthunjaya Uddi, Sang Hee Won, Timothy Ombrello, Campbell Carter, Yiguang Ju "Kinetic effects of nonequilibrium plasma-assisted methane oxidation on diffusion flame extinction limits",Combustion and Flame, 159(1), 221-229, 2012.

[6] M. Juddoo, A.R. Masri, "High-speed OH-PLIF imaging of extinction and re-ignition in non-premixed flames with various levels of oxygenation", Combustion and Flame, 158(5), 902-914, 2011

[7] N. Ding, R. Arora, M. Norconk, S.Y.Lee, "Numerical investigation of diluent influence on flame extinction limits and emission characteristic of lean-premixed H2-CO (syngas) flames", international journal of hydrogen energy, 36, 3222-3231, 2011.

[8] N. Ghiti, A.A. Bentebiche, S. Hanchi, Interaction entre une flamme de diffusion et une paroi verticale, $X^{\text {ème }}$ Colloque Interuniversitaire Franco-québécois sur la Thermique des Systèmes, Saguenay, pp 239-245, 2011.

[9] P.O. Witze, "A study of impinging axisymmetric turbulent flows: the wall jet, the radial jet, and opposing free jets", SAND74- pp. 8257,1975 